\title{
Espiritualidade e Saúde: um olhar por meio de diferentes atores sociais
}

\author{
Spirituality and Health: a look through different social actors \\ Espiritualidad y Salud: una mirada a través de diferentes actores sociales
}

\section{Resumo}

Há tempos, muitas pesquisas vêm sendo realizadas trazendo a relação da espiritualidade e saúde. A Organização Mundial de Saúde desde o final dos anos 70 reconhece o bem-estar espiritual como uma dimensão importante para o equilíbrio do indivíduo, assim, pensar em saúde não é somente remeter a dados biológicos, físicos e mentais, mas a uma busca constante de bem-estar, qualidade de vida e equilíbrio em todos os aspectos da existência. Objetivo: analisar como a espiritualidade pode influenciar na saúde e aspectos emocionais de diferentes atores sociais com crenças e religiões diversas. Metodologia: A pesquisa caracteriza-se como um estudo qualitativo e descritivo, com a finalidade de conhecer e descrever a realidade de diferentes atores sociais com crenças e religiões diversas. Resultados: foi possível perceber que o perfil da amostra são maioria homens (77,8\%), pardos e brancos com 33,3\% cada, com ensino superior completo (50\%), ativos no mercado de trabalho $(66,7 \%)$, renda acima de um salário mínimo $(72,2 \%)$, residentes em zona urbana $(83,3 \%)$, da religião católica $(44,4 \%)$, com nível de qualidade de vida regular $(56,3 \%)$. Considerações finais: As narrativas apontam a espiritualidade como dispositivo pessoal importante para enfrentar as divergências do cotidiano, consequentemente os aspectos que envolvem a saúde. Sugere-se que novos estudos sejam lançados voltados à temática com ênfase no campo e atuação da Terapia Ocupacional.

Palavras-chave: Espiritualidade; Saúde; Religião.

\begin{abstract}
There have been a lot of quality of Life surveys for some time. Since the end of the 1970s, the World Health Organization has recognized spiritual well-being as an important dimension for the balance of the individual, thus, thinking about health is not only referring to biological, physical and mental data, but to a constant search for wellbeing, quality of life and balance in all aspects of existence. Objective: to analyze how spirituality can influence the health and emotional aspects of different social actors with different beliefs and religions. Methodology: The research is characterized as a qualitative and descriptive study, with the purpose of knowing and describing the reality of different social actors with different beliefs and religions. Results: it was possible to perceive that the sample profile is mostly men (77.8\%), brown and white with $33.3 \%$ each, with complete higher education (50\%), active in the labor market $(66.7 \%)$, income above one minimum wage $(72.2 \%)$, living in urban areas $(83.3 \%)$, of the Catholic religion $(44.4 \%)$, with a regular level of quality of life $(56.3 \%)$. Conclusion: The narratives point to spirituality as an important personal device to face daily divergences, consequently the aspects involving health. It is suggested that new studies be launched focused on the theme with an emphasis on the field and performance of Occupational Therapy.
\end{abstract}

Keywords: Spirituality; Health; Religion. 


\section{Resumen}

Desde hace algún tiempo, se vienen realizando muchas investigaciones acercando la relación entre espiritualidad y salud. Desde finales de los años 70, la Organización Mundial de la Salud ha reconocido el bienestar espiritual como una dimensión importante para el equilibrio del individuo, por lo que pensar en la salud no se refiere sólo a datos biológicos, físicos y mentales, sino a una búsqueda constante. para el bienestar, la calidad de vida y el equilibrio en todos los aspectos de la existencia. Objetivo: analizar cómo la espiritualidad puede influir en la salud y aspectos emocionales de diferentes actores sociales con diferentes creencias y religiones. Metodología: La investigación se caracteriza por ser un estudio cualitativo y descriptivo, con el propósito de conocer y describir la realidad de diferentes actores sociales con diferentes creencias y religiones. Resultados: se pudo percibir que el perfil de la muestra es en su mayoría hombres $(77,8 \%)$, pardos y blancos con 33,3\% cada uno, con estudios superiores completos (50\%), activos en el mercado laboral $(66,7 \%)$, ingresos superiores a un mínimo asalariado (72,2\%), residente en zona urbana $(83,3 \%)$, de religión católica $(44,4 \%)$, con nivel regular de calidad de vida $(56,3 \%)$. Consideraciones Finales: Las narraciones apuntan a la espiritualidad como importante dispositivo personal para enfrentar las divergencias cotidianas, consecuentemente los aspectos que envuelven la salud. Se sugiere que se inicien nuevos estudios enfocados en el tema con énfasis en el campo y actuación de la Terapia Ocupacional.

Palabras clave: Espiritualidad; Salud; Religión.

\section{Introdução}

Acredita-se que a ciência e a religião quando são de algum modo interligadas, naturalmente soam de maneira conflituosa. Por muito tempo ambas foram colocadas em contraposição. Apesar das diferenças, Zanini (2019), fortalece a ideia que ambos os temas são essenciais para o conhecimento da realidade e da descoberta do sentido de satisfação que é propenso ao ser humano, porém, são dois modos diferentes e, por isso, se divergem e resulta em conflitos. O autor ainda pontua, que a ciência por si só não consegue dar conta dos problemas que acontecem na humanidade, podendo potencializá-los, portanto, a ciência precisa ser vista em sintonia com a espiritualidade, sem negar a importância da transcendência para interpretar o mundo.

Dessa maneira, de acordo com Gomes, Farina \& Forno (2014) o tema da espiritualidade tem sido tratado em diferentes aspectos, mas principalmente relacionados aos contextos de saúde e bem-estar. Por isso, é importante levar em consideração todas as dimensões que constituem os sujeitos. Ainda assim, é fundamental compreender que a dimensão espiritual, não se trata, "necessariamente, de adesão a uma religião, pois a dimensão espiritual vai além de uma confissão religiosa, não dependendo de lugar, tempo ou código que a defina" (p. 108). Portanto, ao falarmos da espiritualidade é importante compreender que ela:

É universal, ocupa todo nosso ser, toda nossa essência. É uma presença íntima, constante; é parte da nossa vida. Alguns seres humanos são mais espirituais e outros, menos; mas, na verdade, somos todos espirituais e espiritualizados. A espiritualidade está sempre presente no nosso cotidiano, no trabalho, na saúde, na educação, no lazer, na religião, na intimidade de cada um, entre agnósticos e ateus, no deitar, no levantar, enfim, em todos os tempos e momentos da nossa existência (Silva \& Silva, 2014, p. 209)

Quanto às religiões, “elas são compostas por narrativas históricas, símbolos e tradições que se destinam a dar sentido à vida, a explicar sua origem e a do universo" (Ribeiro et al., 2014, p. 1174), a maioria das instituições religiosas tem comportamentos organizados, reuniões regulares, lugares de oração e escrituras sagradas, sendo que de cada uma das religiões derivam códigos de moralidade, ética e leis.

Para o ser humano é mais fundamental compreender a sua espiritualidade do que compreender a sua religião, já que a espiritualidade é uma expressão que caracteriza a totalidade do ser enquanto sentido e vitalidade, sendo caracterizada pela ligação do ser humano com algo maior (Silva et al., 2014). Com isso, "a espiritualidade pode ser uma característica da pessoa religiosa, mas não necessariamente exige participação em práticas e ritos de igreja" (Ribeiro et al., 2014, p. 1774).

Simões, Martins, Santos, Santana et al., (2018) colocam que é perceptível como a espiritualidade influencia em todos os aspectos da vida humana, inclusive auxilia o indivíduo a enfrentar diversos desconfortos que vão surgindo ao longo dela. 
Os autores citam que possuem diversas pesquisas em que a espiritualidade e a religião/religiosidade estão associadas com a redução de estresse, da depressão, de taxas reduzidas de mortalidade, além de trazerem diversos benefícios para a saúde, estimulando o resgate da coragem, ânimo e energia para enfrentar situações de dor e sofrimento.

Portanto, "a espiritualidade gera possibilidades de construírem novos valores, de se adquirirem e conservarem sentimentos mais nobres entre as pessoas, o que vai fazer bem, tanto para saúde física quanto para a saúde mental" (Zanotelli, 2016 p. 57). Com isso, pode se:

Compreender que, ao se tratar da qualidade de vida como dependente de condições e estilos de viver, e ao associar, a esta, a espiritualidade, como elemento para obtê-la, há muitas perspectivas positivas para o século XXI, visto que as duas se fundem em termos de se juntarem sentimentos, valores e outros fenômenos que não se vinculam somente às questões associadas ao bem-estar físico, mas também, ao mental, que, por consequência, se origina na paz interior (Zanotelli, 2016, p. 58).

Corroborando, Seidl et al., (2004) trazem que "A partir da década de 90 estudiosos entram em consenso em relação ao conceito de qualidade de vida, levando em consideração dois aspectos relevantes que é a subjetividade e multidimensionalidade" (p. 582). Ao que diz respeito a subjetividade, os autores citados anteriormente ressaltam a importância em considerar a percepção da pessoa sobre o seu estado de saúde e sobre os aspectos gerais do seu contexto de vida, portanto, essa avaliação de qualidade de vida precisa ser feita pela própria pessoa (Seidl et al., 2004). No que tange à multidimensionalidade, é relevante compreender que a mesma "apresenta uma organização complexa e dinâmica de seus componentes, que difere de pessoa para pessoa de acordo com o seu contexto, mesmo entre pessoas inseridas em um mesmo ambiente" (Pereira et al., 2012 p. 243). Assim, percebe-se a extrema importância em considerar características pessoais do sujeito, como por exemplo: os valores, as crenças e os interesses.

Deste modo, ao falar de saúde é fundamental abordar o conceito de qualidade de vida, tendo em vista que a sua construção surge pela necessidade de uma concepção ampliada de saúde que integre todas as dimensões envolvidas nesse processo. Segundo Melo, Sampaio, Souza \& Pinto (2015, p. 458) “ao se deparar com o sujeito nas práticas de saúde, deve-se ter o compromisso de utilizar meios humanizados para tal, buscando entender o que é saudável para ele e, consequentemente, oferecer espaço para a sua subjetividade". Entendendo também que a religiosidade e a espiritualidade podem ser elementos constituintes da subjetividade dos indivíduos.

De acordo com Mângia (2000) com todas as mudanças que vieram ocorrendo no cuidado aos usuários, o terapeuta ocupacional modifica o seu objeto, propondo, assim, um investimento na vida cotidiana da pessoa, deixando de intervir apenas na doença e nos sintomas, considerando ser por intermédio da relação com o meio que o sujeito restaura sua cidadania e dá sentido à sua vida. Dessa maneira, o elo afetivo entre terapeuta e usuários, caminha em um sentido de relação humana, no que envolve a relação terapêutica, possibilitando estar com o outro na sua essência, subjetividade, dificuldades, potências, crenças e contextos (Marcolino, 2009)

"No campo da Terapia Ocupacional, mesmo considerando as diferenças culturais e históricas de cada país, a questão da espiritualidade sempre esteve, ainda que de forma intermitente, na pauta das discussões” (Araújo et al., 2014, p. 3). Os autores citam uma fala de Danton, um dos precursores da profissão, na qual ele traz quando fala das qualidades da ocupação que esta é tão necessária para a vida como a comida e a bebida e que as enfermidades da mente, do corpo e do espírito podem sanar através da ocupação, ou seja, percebemos a dimensão espiritual presente enquanto algo inseparável do ser humano e que podem ter influências por meio da ocupação. Entretanto, apesar do aumento de pesquisas sobre o tema, ainda existe uma enorme "lacuna entre a teoria e a prática, entre reconhecer a importância da espiritualidade e efetivamente incorpora-la à prática clínica.” (p. 3). Por isso, o terapeuta ocupacional ainda tem um difícil percurso relacionado a incorporar questões de cunho espiritual no universo acadêmico e profissional. 
Com isso, de acordo com Peres et al., (2007, p. 83) "a atenção ao aspecto da espiritualidade se torna cada vez mais necessária na prática de assistência à saúde". Assim, esta pesquisa tem como objetivo analisar como a espiritualidade pode influenciar na saúde e aspectos emocionais de diferentes atores sociais com crenças e religiões diversas.

\section{Metodologia}

A presente pesquisa possui natureza qualitativa e descritiva. A pesquisa qualitativa segundo Minayo (2009, p. 21) refere-se a questões particulares, na qual" trabalha com o universo dos significados, dos motivos, das aspirações, das crenças, dos valores e das atitudes". Trata-se de uma ciência social com um nível de realidade que não pode ser mensurada, pois todos fenômenos humanos citados anteriormente, pertence a uma realidade em que o sujeito se difere e se reconhece, não só por agir, mas também por pensar sobre o que faz e por interpretar suas ações dentro e a partir das suas experiências no contexto em que o mesmo é inserido.

Destacamos que a presente pesquisa também se caracteriza como descritiva, compreendendo que o processo descritivo tem por objetivo identificar, registrar e analisar variáveis ligadas ao fenômeno estudado, proporcionando novas visões sobre a realidade explorada (Nunes, Nascimento \& Luz, 2016)

Devido ao período de crise sanitária da Pandemia ocasionada pelo novo Coronavírus - COVID-19, com consequente adaptações nas atividades de ensino, pesquisa e extensão, esta pesquisa foi realizada de maneira remota por meio da plataforma Google-Meet e formulários online pelo Google-forms.

A amostra foi por conveniência a partir da estratégia snowball com recrutamento em redes sociais, organizações representativas e mídias sociais. Foi realizado um mapeamento de líderes (sociais, comunitários, culturais, políticos, empresariais e religiosos), a partir de comunidades em redes sociais, contato com representações e associações por meio de telefone e/ ou e-mail. A partir do levantamento desta população, os pesquisadores responsáveis delimitaram uma amostra por cálculo amostral. Para esta pesquisa totalizou dezoito participantes de ambos os sexos, com dezoito anos ou mais de idade, líderes sociais, comunitários, culturais, políticos, empresariais e religiosos.

A pesquisa foi desenvolvida conforme as diretrizes da Resolução CNS 466/2012, com as atualizações disponíveis na Resolução CNS 510/2016. Além disso, por se tratar de uma pesquisa realizada em ambiente online, levou em consideração as recomendações contidas na Carta Circular $n^{\circ}$ 1/2021-CONEP/SECNS/MS, que trata sobre as orientações para procedimentos em pesquisas com qualquer etapa em ambiente virtual. Além disso, foi garantido o anonimato dos participantes, em todas as publicações decorrentes da mesma, sendo compromisso assumido pelas pesquisadoras. A presente pesquisa faz parte do projeto de pesquisa A Essência Humana: sentimentos, emoções e afetos, uma viagem pela vida sob o olhar de diferentes atores sociais, só foi executada após aprovação do Comitê de Ética e Pesquisa, CAAE: 29943520.9.0000.5546, processo nº4.490.562. Para participar da pesquisa os participantes preencheram o Termo de Consentimento Livre e Esclarecido online (TCLE), clicando na opção que afirma que concordavam em participar da pesquisa. No TCLE estavam explicitados os objetivos da pesquisa, o formato de coleta de dados, a garantia do anonimato e a forma de utilização dos dados provenientes da investigação.

A coleta de dados foi feita em dois momentos após a assinatura do TCLE. O Primeiro por meio do emprego de um questionário com dados pessoais e sócio demográficos como idade, profissão, estado civil, naturalidade, religião e, no segundo momento, utilizou-se uma entrevista aberta por plataforma digital (GOOGLE-MEET), seguindo o roteiro criado pelas pesquisadoras. O período de coleta de dados foi de agosto de 2020 a julho de 2021. Inicialmente os participantes receberam um convite via e-mail, neste convite apresentava-se toda a pesquisa, com seus objetivos e forma de coleta de dados.

A entrevista foi realizada de maneira individual e foi agendada conforme a disponibilidade dos pesquisadores e participantes. Durante as entrevistas, foi permitido que os participantes falassem de maneira livre, a respeito das questões 
abordadas a partir de suas experiências cotidianas, culturais e contexto em que se encontravam, por isso, a duração das entrevistas foram variáveis, com no mínimo 1 hora e no máximo 4 horas de duração. Foram feitas dezesseis perguntas abertas, no entanto, para este estudo utilizou apenas as seguintes perguntas:

\section{“Qual o significado de fé para você?" \\ “Qual o significado de oração para você??" \\ Qual o significado de saúde para você?"”}

As entrevistas foram gravadas na íntegra pela plataforma do google meet, para fins, exclusivamente, da pesquisa. Tendo o material das entrevistas gravado e transcrito, foram realizadas leituras flutuantes, com o intuito de familiarizar com os conteúdos, tomando contato com os documentos a serem analisados, conhecendo o contexto e deixando fluir impressões e orientações. A técnica empregada foi baseada nos pressupostos de Minayo, compreendendo o percurso da análise sistemática dos dados a partir dos significados imersos em elementos como valores, crenças, trocas, ações humanas e relações entre os atores sociais (Minayo, 2012). Desta forma, a análise qualitativa de um objeto de investigação concretiza a possibilidade de construção de conhecimento e possui todos os requisitos e instrumentos para ser considerada e valorizada como um construto científico. A análise dos dados qualitativos surge a partir das respostas das perguntas: “Qual o significado de fé para você?

\section{Qual o significado de oracão para você?? Qual o significado de saúde para você??".}

Assim, para melhor visualização dos dados, os resultados foram distribuídos em três temas, sendo que estes temas foram escolhidos de acordo com estas três perguntas relatadas acima durante a entrevista com os participantes.

\section{Resultados e Discussão}

Dentre os dezoito participantes da pesquisa que responderam o questionário sócio demográfico e participaram da entrevista, 22,2\% (n=4) eram mulheres e 77,8\% (n=14) homens, sendo que nenhum deles possuía deficiência. Com relação a raça/etnia, 33,3\% $(n=6)$ eram brancos, 27,8\% $(n=5)$ negros, 33,3\% $(n=6)$ pardos e 5,6\% $(n=1)$ eram outros. Relacionado a escolaridade, $5,6 \%(n=1)$ tinha o ensino fundamental incompleto, 11,1\% $(n=2)$ com ensino fundamental completo, $11,1 \%$ $(\mathrm{n}=2)$ com ensino médio incompleto, $5,6 \%(\mathrm{n}=1)$ com ensino médio completo, $16,7 \%(\mathrm{n}=3)$ com ensino superior incompleto e $50 \%(\mathrm{n}=9)$ com ensino superior completo. Todos participaram dos dois momentos da pesquisa.

Já com relação ao trabalho, 66,7\% $(\mathrm{n}=12)$ se apresentavam ativo no mercado de trabalho, 11,1\% (n=2) desempregados e 22,2\% (n=4) aposentados, sendo que a renda mensal variava entre menos de um salário mínimo 5,6\% (n=1), um salário mínimo 22,2\% (n=4) e acima de um salário mínimo 72,2\% (n=13). No aspecto moradia, 83,3\% (n=15) moravam na zona urbana e 16,7\% $(\mathrm{n}=3)$ na zona rural, a maioria morando com outras pessoas 88,9\% (n=16). A religião dos participantes variou entre 44,4\% $(\mathrm{n}=8)$ católica, umbanda 5,6\% ( $\mathrm{n}=1)$, Santo Daime 5,6\% ( $\mathrm{n}=1)$, espírita 5,6\% ( $\mathrm{n}=1)$, Candomblé 5,6\% $(n=1)$, Wicca 5,6\% $(n=1)$, Ateu 5,6\% $(n=1)$ e outros 22,2\% $(n=4)$.

Dando continuidade ao processo de compreensão dos significados de fé, oração e saúde apontados pelos participantes desta pesquisa, inicia-se o processo de apropriação do conteúdo das entrevistas para assim chegar a organização de temas que nos permitiram alcançar os pontos centrais para nossa análise.

\section{$1^{\circ}$ tema: fé}

Batista (2018) compartilha em sua tese sobre uma nova área de investigação que é a Neuroteologia, que se propõe a ter uma melhor compreensão sobre a mente humana, a religião e tudo que compõem esses dois universos que é a ciência e a espiritualidade, sem anular nenhuma dessas áreas. O autor relata que ao estudar a Neuroteologia, "os pesquisadores buscam compreender a ligação entre as diferentes áreas e funções do cérebro e como elas podem auxiliar ou impedir, em termos de desenvolvimento da espiritualidade humana" (Batista, 2018, p. 15). 
De acordo com Batista (2018) ao estudar a espiritualidade e tudo que a permeia, é primordial refletir sobre alguns conceitos. Portanto, é importante entender que fé e crença são termos que a maioria das pessoas confunde ou acredita que são sinônimos. Porém, não são idênticos, mas sim conceitos que estão relacionados, já que ambos não precisam de provas para comprovar a sua existência. O autor define:

O termo crença como sendo qualquer percepção, cognição ou emoção que o cérebro assume consciente ou inconscientemente, como sendo verdade. O termo fé pode ser definido como uma crença que não necessita de evidências e que está particularmente fundamentada na ideia de uma revelação especial feita pelo divino (p. 28).

Já Amatuzzi (2003, p. 570) entende que “a fé seria, então, a ligação com o esperado, a determinação da ação, o vivido de uma opção que mobiliza todo o ser". O mesmo defende a ideia de que a fé é intrínseca ao ser humano, mesmo que a pessoa não seja religiosa, sempre terá fé, pois necessita dela, já que ela que dá sentido à vida (Amatuzzi, 2003).

"[...] é algo natural, todo mundo tem, até o ateu tem fé, o ateu crê na ciência. Então todo mundo tem fé [...]” (Participante 12).

Sousa (2019) também apresenta em seu estudo a ideia de que "é quase impossível até de imaginar a vida sem fé” (p. 84), entendendo que as pessoas possuem fé, nem que seja em instituições, em pessoas, ou até mesmo fé em si mesmo.

\section{“[...] acho que é acreditar muito em algo. Por exemplo, eu tenho muita fé em mim mesmo [...]” (Participante $13)$.}

Corroborando com essa ideia, Araújo, Oliveira \& Jaramillo (2014) trazem que "não apenas objetos e coisas podem assumir o caráter Sagrado e suscitar a espiritualidade de uma pessoa, mas também muitos outros elementos de sua rotina como uma música, um cheiro, um alimento, um gesto, uma atividade específica" (p. 9), pois os autores trazem que essa experiência do Sagrado é subjetiva, ou seja, fundamenta-se de maneira pessoal. "Em 2002 a American Occupacional Therapy Assciation (AOTA) incluiu a espiritualidade na Occupational Therapy Practice Framework: Domain and Process". Deste modo, para os autores pensar no cuidado do terapeuta ocupacional nesta vertente, aos autores complementam que:

É possível que ocorra uma via de dupla afetação na relação que se pode estabelecer entre ocupação e espiritualidade, ou seja, a espiritualidade poderá manifestar-se através do engajamento em uma ocupação, do mesmo modo que uma ocupação poderá ter sua forma, função e significado alterados quando ela se encontrar sob a dimensão espiritual de um determinado cliente, sob a esfera do Sagrado e/ou com frequência, do religioso, o que, no processo terapêutico ocupacional, poderá gerar inúmeras demandas que exigirão do terapeuta não apenas manejo técnico, mas uma postura que reconheça a espiritualidade como um modo de ser amplo e profundo, que toca praticamente todas as dimensões da vida do cliente e que ultrapassa um conjunto definido de crenças, práticas, relações e experiências (Araújo, Oliveira \& Jaramillo, 2014, p. 10).

\section{$2^{\circ}$ tema: oração}

Para Silva (2018, p. 7), a oração é um “fenômeno universal”, que independentemente de qualquer religião, a prática estará presente na experiência humana. O autor ainda alega que cada sujeito tem a sua forma de orar, e de maneira individual cada um vai expressa-la, seja de maneira simples ou complexa, mas que essa comunicação ocorrerá de maneira espontânea. Dantas, Melo \& Carvalho (2019) "A oração não se trata somente de perguntas e respostas entre a criatura e o criador, mas de uma vivência da realidade" (p. 163). 
"[...] oração é conexão, é conversar, oração é, eu diria que é exatamente você fazer essa conexão com essa vida, com tudo, com o que eu chamo de movimento e pode dar vários nomes, então você estar conectado com ele, com essa força, com esse movimento, com a vida [...]" (Participante 09).

Martins (2019) também compartilha da ideia que a oração é uma forma de comunicação e é por meio dela que existe toda expressão transmitida em uma mensagem por meio da relação entre o sujeito e Deus.

\section{“[...] é uma forma de comunicação com o transcendente, com Deus[...]” (Participante 12).}

A autora pontua que ao buscar no dicionário a palavra oração, uma das definições que é apresentada é o verbo pedir, assim, acredita que essa ideia de oração como um ato de clamar seus desejos aos céus está muito consolidada na sociedade. Portanto, em sua pesquisa ela traz conceitos afim de ampliar essa ideia de oração, compreendendo que além de ser uma forma de se comunicar com o transcendente, ela ocorre de diversas maneiras, portanto, defende a ideia de que a comunicação verbal é uma das formas de expressão, porém, não é a única já que “a oração precede às palavras, ela começa no coração e muitas vezes não pode ser traduzida no discurso [...]” (Martins, 2019, p. 89)

“[...] é um telefone, quando a gente é criança, não sei se você já ouviu aquela musiquinha "o telefone dos céus é a oração". A oração ela é um mundo de conexões sabe, muito poderoso. A oração é uma ferramenta que tem esse poder de elevar o nosso padrão vibracional, para fazer com que a gente não atraia coisas que prejudiquem nosso desenvolvimento seja pessoal, mental, emocional, espiritual [...]” (Participante 15).

A maioria dos participantes ao apresentar as suas concepções acerca do tema, demonstra o quanto a oração é fundamental em seu cotidiano, e o quanto os fortalece, e os conecta com uma força maior, como pode ser ilustrado na fala do participantes 02 .

“[...] oração é importante, é muito importante, é muito importante orar, porque quem “tá” orando "tá” se lembrando de Deus [...]”" (Participante 02).

Gonçalves, Nacimento \& Santos (2018) alegam que "O primeiro benefício da oração é a transformação interior na busca da paz e o segundo, a esperança na graça a ser alcançada”. (p. 94)

“(...) você ter uma relação com Deus, com um ser superior, e que você acredita que é importante para você, que existe, que lhe protege, dependendo do credo, cada um vai pensar de uma forma nesse sentido, mas que você quer "tá" em diálogo constantemente, pedindo proteção, agradecendo, desabafando aquilo que 'tá no seu coração (...) isso traz segurança e paz [...]” (Participante 14).

Baldicera \& Trindade (2011, p. 7) em um trabalho intitulado: Depressão em religiosos: existe influência da religiosidade e espiritualidade? Trazem que "a Terapia Ocupacional tem como objeto de estudo a ocupação humana, seu cotidiano, sua rotina e na vida religiosa pesquisada, percebe-se que a oração, meditação, estudo, leitura e partilha estão inseridas, incondicionalmente, na rotina deste público”, para os autores isso favoreceria o baixo nível de depressão. Portanto, por meio dos resultados que obtiveram na pesquisa, inserir a atividades religiosas, independente de "qual for, no cotidiano do sujeito fortalecerá a autoestima, a socialização, assim como a prática da oração ou meditação reforça a energia mental, beneficiando mente e corpo, o sujeito torna-se calmo e limpa a sua mente de outros pensamentos ou seja contribuirá significativamente na sua saúde" (Baldicera et al., 2011, p. 11).

Silva (2013) traz que a espiritualidade é de extrema importância durante uma hospitalização prolongada, principalmente para que os pacientes e familiares consigam aceitar a doença com uma maior "esperança, conforto, a qualidade 
de vida e o bem-estar, principalmente em caso de doenças ameaçadoras da vida" (Silva, 2013, p. 29). Em seu texto, Pinto e Ribeiro (2007) trazem que reconhecem que os pacientes desejavam a compreensão dos profissionais relacionadas a suas crenças, pois assim, vão conseguir enxerga-los como sujeitos e não apenas um diagnóstico, os ajudando ultrapassar as dificuldades e barreiras, acolhendo e ouvindo cada um deles de maneira significativa. Essas questões corroboram com a forma de atuação do terapeuta ocupacional, pois, este é um profissional que acolhe os diferentes diagnósticos trazidos, não os excluindo, no entanto, não se limitando a nenhum deles, pois, permite um olhar para além destas questões, permitindo ver as fragilidades, mas, também, as potências, contextos, desejos e sonhos. Por isso, a espiritualidade e crenças precisam serem valorizadas durante todo o processo terapêutico.

\section{$3^{\circ}$ tema: saúde}

Segundo Scliar (2007) tanto o conceito de saúde quanto de doença, é subjetivo e individual, pois, as suas definições é relativa e vai depender dos valores individuais, das concepções cientificas, religiosas e filosóficas de cada um. Além disso, ambos os conceitos foram se modificando ao longo do tempo, havendo bastante transformações de acordo com a época e a cultura vivenciada. É essencial compreender que “essas definições envolvem desde ações de políticas públicas de um determinado Estado a comportamentos da população diante das questões de saúde apresentadas em seu ambiente, possibilitando diversos manejos e formas de cuidado" (Comin \& Figueiredo, 2018, p. 884).

“[...] saúde é você correr, é poder se exercitar, é poder viver a sua vida na naturalidade, para mim isso é saúde, caminhar, correr, fazer sexo com a esposa, é brincar de bola com as crianças, com os filhos, para mim isso é saúde [... ]" (Participante 06).

"[...] é eu poder trabalhar, é eu poder me movimentar, porque eu tenho muita dor na coluna, mas, enquanto eu estiver fazendo isso, para mim é saúde. Eu adoro trabalhar [...]” (Participante 11).

$\mathrm{Na}$ antiguidade alguns autores como Descartes acreditavam que a mente e o corpo funcionavam separadamente, sendo o corpo visto como uma máquina (Andrade \& Muller, 2006). Pensamento esse que influenciou por muito tempo a medicina e a sua visão reducionista. Já a medicina psicossomática possui uma visão holística, em que acredita que existe a relação entre fatores psicossociais e biológicos no curso da doença, por isso, sendo de grande importância, pensar na saúde em todos os seus aspectos. A maioria dos entrevistados traz uma visão sobre saúde que vai além do campo biológico, pois muitos acreditam que a saúde é:

“[...] bem-estar em todos os sentidos: mentalmente, fisicamente e sentimentalmente, estar bem nas nossas relações: de trabalho, com a família, esse é o bem-estar! É aquilo que a gente busca sempre: bem-estar com você e com o outro [...]" (Participante 08).

“[...] é um estado onde meu físico esteja sem nenhum problema e o meu mental também [...]” (Participante 13).

“ [...] saúde é algo de bom, a pessoa ter saúde é muito bom. Por isso, que a gente procura viver em tranquilidade na praça, para que a gente tenha saúde tanto mental como no corpo. De corpo, coração e alma, porque se a pessoa não tiver saúde algo não vai sair certo [...]”" (Participante 01)

Thurow, Charão, Mortagua \& Souza (2017) acreditam que o bem-estar espiritual, ajuda em vários aspectos da vida, criando experiência de fortalecimento e apoio pessoal para enfrentar mudanças, resultando em uma melhora na qualidade de vida e interferindo diretamente na saúde do sujeito, seja física ou mental. A Organização Mundial de Saúde (OMS) inclui a dimensão espiritual em seu conceito de saúde, concluindo que "é o estado dinâmico de completo bem-estar físico, mental, espiritual e social e não apenas a ausência de doença ou enfermidade" (p 80). 
“[...] é a saúde espiritual que é que eu mais tenho falado nos últimos tempos, que muitas pessoas negligenciam e partindo do meu ponto de vista, saúde espiritual não que seja a mais importante, mas eu acredito que a visão sobre ela deveria ser um pouquinho mais [pausa] sabe prestar mais atenção, cuidar um pouco melhor. Porque tudo acontece primeiro a nível espiritual [...]. Então, a doença ela é a manifestação física de uma coisa que já tinha se projetado no corpo espiritual há muito tempo [...]" (Participante 15).

“(...) a saúde, que além da dimensão física, corporal, diz respeito também aos aspectos psicológicos ou mentais e, espirituais, então, está mais relacionada a um equilíbrio entre essas esferas, ou seja uma Harmonia entre os planos espirituais e materiais da vida; bom é importante notar que a palavra latina salus, que dá origem à palavra saúde é a mesma raiz que também origina a palavra salvação e realmente pra nós daimistas não existe muita separação entre esses planos, pois, qualquer doença quando vem a se manifestar no plano orgânico já deve estar anteriormente relacionada a algum desequilíbrio nas esferas psíquicas ou espirituais [...]" (Participante 10).

De acordo com Martins (2010) “saúde é um conceito amplo e complexo”, portanto, para falar que alguém tem saúde, é necessário "passar por todas as dimensões constituintes do ser humano [...] na qual saúde não é apenas ausência de moléstia, mas completo bem-estar físico, social, mental e espiritual” (p 551), no entanto, para o autor a maior preocupação dele enquanto profissional de saúde não seria saber quando o usuário alcança este completo bem-estar, mas no cuidado do usuário, aliviando o sofrimento e não tendo a pretensão de sanar completamente este:

Holismo e bem-estar são dois termos chaves para a compreensão do desenvolvimento das pesquisas que correlacionam saúde e espiritualidade. O primeiro foi a "senha" para a legitimação de pesquisas sobre terapêuticas que se baseavam no princípio de uma conexão entre corpo e mente. O segundo, que se estabeleceu como um importante indicador de saúde nos instrumentos estatísticos de controle da população, incorporou, na década de 1990, a variável "espiritualidade" para a composição de seus resultados (Toniol, 2015, p. 119).

Ainda de acordo com Toniol (2015), em seus estudos a maioria dos textos traz uma conexão positiva entre espiritualidade, cura, recuperação e bem-estar. Além disso, traz que esta influência da espiritualidade sobrevém tanto nos aspectos físicos como emocionais dos sujeitos, ou seja, a:

Espiritualidade tem a capacidade de transpassar as possíveis fronteiras entre essas "partes", encarnando de modo emblemático o caráter holístico da saúde humana. Ao ser mobilizada como um valor universal, enquanto dimensão inerente a todos os humanos e como invariavelmente positiva à saúde, a espiritualidade, nas pesquisas médicas, deixa de ser um objeto de investigação para tornar-se uma recomendação (Toniol, 2015, p. 127).

Dessa maneira, vemos a Organização Mundial de Saúde em 1998 inserindo a espiritualidade no conceito de saúde como uma das dimensões, além das políticas públicas iniciarem o reconhecimento desta dimensão. Mais uma vez, podemos trazer a terapia ocupacional relacionando esta vertente, na qual prioriza um acolhimento integral, no qual cada sujeito é visto como único, integrante de um contexto, fazendo parte de uma cultura, assim, consegue articular e integrar a pessoa como um todo, ou seja, é necessário incluir em todo o processo uma "totalidade individualizante, cuja marca é sintetizada pela tríade corpo-mente-espírito. Isso é, se a totalidade da primeira inclui um pertencimento à comunidade, a da segunda incide em um sujeito que pode ser descrito como uma espécie de mônada, encerrado em si mesmo" (Toniol, 2015, p. 132/133).

\section{Considerações Finais}

É perceptível tamanha subjetividade que permeia a saúde e a espiritualidade. Os resultados analisados na coleta de dados apontam a espiritualidade como dispositivo pessoal importante para enfrentar as divergências do cotidiano. E o quanto a saúde é influenciada por ela, estando relacionada em todos os aspectos da vida dos sujeitos. Assim, pelas falas observamos que ambos os temas se apresentam entrelaçados e fazendo parte da totalidade humana. Portanto, é fundamental enfatizar a 
necessidade de pesquisar mais sobre a temática saúde e espiritualidade.

\section{Referências}

Ammatuzi, M. M. (2003) Fé e Ideologia na Compreensão Psicológica da Pessoa. Psicologia: Reflexão e Crítica, 16 (3), $569-575$.

Araújo, L. S \& Oliveira, I. B. S \& Jaramillo, S. R. (2014) Espiritualidade e a Prática da Terapia Ocupacional: Interfaces no campo da ocupação humana. TOG (A Coruña), 11 (20).

Baldicera, C. R \& Trindade, M. N. P. (2011) Depressão em Religiosos: Existe Influência da Religiosidade e Espiritualidade? (TCC para graduação em Terapia Ocupacional), Santa Maria, RS.

Batista, L. A. (2018) Neuroteologia: Fundamentos e Perspectivas. (Dissertação em Ciências da Religião), São Paulo.

Castro, M. G; Andrade, T. M. R \& Muller, M. C (2006). Conceito mente e corpo através da história. Psicologia em Estudo, Maringá, 11.(1), 39-43, jan./abr.

Comin, F. S \& Figueiredo, I. A (2018). Concepções de saúde, doença e cuidado em Primeiras estórias, de Guimarães Rosa. Saúde e Sociedade. São Paulo, 27 (3), 883-897.

Dantas, I. D. O; Melo, W. P. P \& Carvalho, R. R. F (2019). A oração na bíblia e nas comunidades cristãs. I Semana Nacional de Teologia, Filosofia e Estudos de Religião I Colóquio Filosófico: Filosofia e Religião.

Gomes, N. S.; Farina, M. \& Forno, C. D (2014). Espiritualidade, Religiosidade e Religião: Reflexão de Conceitos em Artigos Psicológicos. Revista de Psicologia da IMED, 6 (2), 107-112.

Gonçalves, H. A; Nascimento K. C. S \& Santos, A. P. A. L (2018). Espiritualidade e Religiosidade: A fé cristã e o papel da oração no processo de enfrentamento da doença. Paralellus, Recife, 9 (20).

Marcolino, T. Q (2009). A porta está aberta: aprendizagem colaborativa, prática iniciante, raciocínio clínico e terapia ocupacional. (Tese de doutorado), Universidade Federal de São Carlos, São Carlos.

Mângia, E, F (2000). A trajetória da terapia ocupacional da psiquiatria às novas instituições e estratégias de promoção de saúde mental. Revista de Terapia Ocupacional da Universidade de São Paulo, São Paulo, 11 (1), 28-32.

Martins, P. M. F (2019). A oração além das palavras. Revista. Terra \& Cultura., Londrina, 35 (68), jan./jun.

Martins, A. A (2010). A pastoral da Saúde e sua importância no mundo da saúde: da presença solidária ao transcender a dor e o sofrimento. $O$ Mundo da Saúde, São Paulo, 34 (4): 547-552.

Melo, C. F; Sampaio, I. S; Souza, D. L. A \& Pinto, N. S (2015). Correlação entre religiosidade, espiritualidade e qualidade de vida: uma revisão de literatura. Estududos e Pesquisas em Psicologia., Rio de Janeiro, 15 (2), 447-464.

Minayo, M. C. S (2009). Pesquisa Social. Teoria, método e criatividade. 28 ed. Petrópolis: Vozes.

Minayo, M. C. S. (2012). Análise qualitativa: teoria, passos e fidedignidade. Ciência \& Saúde Coletiva, 17 (3), $621-626$.

Nunes, G. C.; Nascimento, M. C. D \& Luz, M. A. C. A (2016). Pesquisa Científica: conceitos básicos. Id on Line Revista Multidisciplinar e de Psicologia, 10 (29).

Peres, M. F. P. Arantes, A. C. L. Q, Lessa, S. P \& Caous C. A (2007). A importância da integração da espiritualidade e da religiosidade no manejo da dor e dos cuidados paliativos. Revista de Psiquiatria Clínica, 34 (1), 82-87.

Pereira, E. F; Teixeira, C. S \& Santos, A (2012). Qualidade de vida: abordagens, conceitos e avaliação. Revista Brasileira de Educação Física e Esporte, São Paulo, $26(2), .241-50$.

Pinto, C. \& Ribeiro, J. L. P (2007). Construção de uma escala de avaliação da espiritualidade em contextos de saúde. Arquivos de Medicina, Porto Seguro, 21 (2).

Ribeiro, F. M. L \& Minayo, M. C. S (2019). O papel da religião na promoção da saúde, na prevenção da violência e na reabilitação de pessoas envolvidas com a criminalidade: revisão de literatura. Ciência \& Saúde Coletiva, 19 (6), 1773-1789.

Scliar, M (2007). História do Conceito de Saúde. PHYSIS: Revista Saúde Coletiva, Rio de Janeiro, 17 (1)29-41

Seidl, E. M. F \& Zannon, C. M. L. C (2004). Qualidade de vida e saúde: aspectos conceituais e metodológicos. Cadernos de Saúde Pública, Rio de Janeiro, 20 (2), 580-588.

Silva, J. B \& Silva, L. B (2014). Relação entre Religião, Espiritualidade e Sentido da Vida. Revista da Associação Brasileira de logoterapia e Análise Existencial; 3 (2), 203-215.

Silva, M. S (2013). A Espiritualidade Na Atenção Em Saúde Em Geral no Brasil. (TCC para graduação em Terapia Ocupacional), Universidade de Brasília, Faculdade de Ceilândia.

Silva, O. G (2018). A importância da oração para uma vida de fé. (Dissertação) em Teologia. São Leopoldo. 
Research, Society and Development, v. 11, n. 2, e41311225874, 2022

(CC BY 4.0) | ISSN 2525-3409 | DOI: http://dx.doi.org/10.33448/rsd-v11i2.25874

Simões, N. D, Martins, P. G, Santos, R. O. P, Santana, F. R \& Pilger, C (2018). Espiritualidade e saúde: experiência de uma disciplina na graduação de enfermagem. Revista de Enfermagem, 181-191.

Thurow, A. C, Charão, C. S, Mortagua, E. O, \& Souza, L, M (2017). Bem-Estar Espiritual e Religião em Doutorandos de Universidade Comunitária. Revista de Psicologia da IMED, Passo Fundo, 9 (2), 77-92.

Toniol, R. (2015) Espiritualidade que faz bem. Pesquisas, Políticas Públicas e Práticas Clínicas pela Promoção da Espiritualidade da Espiritualidade como Saúde. Sociedad y Religión, 43 (XXV), 110-143.

Zanini, R. L. (2019) Religião e Ciência: caminho de aliança ética. Caderno teológico da PUC PR; 1, 91-104.

Zanotelli, M. I. G. (2016) Espiritualidade e qualidade de vida: perspectivas para o século XXI. (Dissertação) em Religião e Esfera Pública. 